NASA/TM-1999-208910

AIAA-99-0319

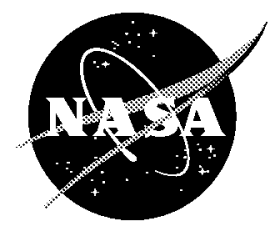

Telescience Operations on International Space Station

Kathleen E. Schubert

Lewis Research Center, Cleveland, Ohio 
Since its founding, NASA has been dedicated to the advancement of aeronautics and space science. The NASA Scientific and Technical Information (STI) Program Office plays a key part in helping NASA maintain this important role.

The NASA STI Program Office is operated by Langley Research Center, the Lead Center for NASA's scientific and technical information. The NASA STI Program Office provides access to the NASA STI Database, the largest collection of aeronautical and space science STI in the world. The Program Office is also NASA's institutional mechanism for disseminating the results of its research and development activities. These results are published by NASA in the NASA STI Report Series, which includes the following report types:

- TECHNICAL PUBLICATION. Reports of completed research or a major significant phase of research that present the results of NASA programs and include extensive data or theoretical analysis. Includes compilations of significant scientific and technical data and information deemed to be of continuing reference value. NASA's counterpart of peerreviewed formal professional papers but has less stringent limitations on manuscript length and extent of graphic presentations.

- TECHNICAL MEMORANDUM. Scientific and technical findings that are preliminary or of specialized interest, e.g., quick release reports, working papers, and bibliographies that contain minimal annotation. Does not contain extensive analysis.

- CONTRACTOR REPORT. Scientific and technical findings by NASA-sponsored contractors and grantees.
- CONFERENCE PUBLICATION. Collected papers from scientific and technical conferences, symposia, seminars, or other meetings sponsored or cosponsored by NASA.

- SPECIAL PUBLICATION. Scientific, technical, or historical information from NASA programs, projects, and missions, often concerned with subjects having substantial public interest.

- TECHNICAL TRANSLATION. Englishlanguage translations of foreign scientific and technical material pertinent to NASA's mission.

Specialized services that complement the STI Program Office's diverse offerings include creating custom thesauri, building customized data bases, organizing and publishing research results ... even providing videos.

For more information about the NASA STI Program Office, see the following:

- Access the NASA STI Program Home Page at http://www.sti.nasa.gov

- E-mail your question via the Internet to help@sti.nasa.gov

- Fax your question to the NASA Access Help Desk at (301) 621-0134

- Telephone the NASA Access Help Desk at (301) 621-0390

- Write to:

NASA Access Help Desk

NASA Center for AeroSpace Information 7121 Standard Drive

Hanover, MD 21076 
NASA/TM-1999-208910

AIAA-99-0319

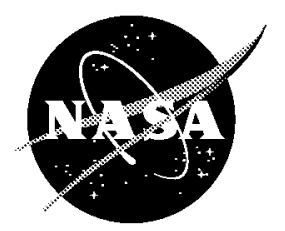

\section{Telescience Operations on International Space Station}

Kathleen E. Schubert

Lewis Research Center, Cleveland, Ohio

Prepared for the 37th Aerospace Sciences Meeting and Exhibit sponsored by the American Institute for Aeronautics and Astronautics Reno, Nevada, January 11-14, 1999

National Aeronautics and Space Administration

Lewis Research Center 


\section{Acknowledgments}

The TSC development is performed within the Microgravity Science Division (MSD) of the NASA Lewis Research Center (LeRC). The Analex Corporation, the Dynacs Engineering Company, Inc., and

White's Information Systems, Inc support the activity.

This report contains preliminary

findings, subject to revision as analysis proceeds.

Available from

NASA Center for Aerospace Information 7121 Standard Drive

Hanover, MD 21076

Price Code: A03
National Technical Information Service 5285 Port Royal Road Springfield, VA 22100 Price Code: A03 


\title{
Telescience Operations on International Space Station
}

\author{
by Kathleen E. Schubert, NASA-Lewis Research Center, Cleveland, Ohio
}

\begin{abstract}
This paper describes the concept of telescience operations for the International Space Station (ISS). The extended duration microgravity environment of the ISS will enable microgravity science research to enter into a new era of increased scientific and technological data return. The National Aeronautics and Space Administration (NASA) has a vision of distributed ground operations which enables the Principal Investigator direct interaction with his/her on-board experiment from his/her home location. This is the concept of telescience and is essential for maximizing the use of the long duration science environment that ISS provides. The goal of telescience is to provide the capability to fully tele-operate an experiment from any ground location in such a way as to increase the amount and quality of scientific and technological data return and decrease the operations cost of an individual experiment relative to the era of Space Shuttle experiments. This paper also describes the NASA Lewis Research Center (LeRC) implementation approach for the LeRC Telescience Support Center (TSC) and Principal Investigator Science Operations Sites (SOS) which will fully meet the concept of telescience as prescribed by the Agency.
\end{abstract}

\section{$\underline{\text { Introduction }}$}

The NASA Microgravity Research Program Office (MRPO) advocates and coordinates an interdisciplinary research community to conduct specified research and to disseminate the results of that research. Research selected for flight definition are assigned to a carrier or a research facility best suited for that experiment (Space Shuttle, International Space Station, Glovebox, etc.). NASA Lewis Research Center (LeRC) is responsible for the development and operation of individual flight experiments and a research facility on the International Space Station to perform numerous microgravity investigations in combustion and fluid science research.
The emphasis of this paper is on the telescience ground operations required for the ISS. The ISS is an earth orbiting facility which houses experiment payloads, distributes resource utilities, and supports permanent human habitation for conducting experiments with research and science payloads in a microgravity environment. The ISS operates continually on an increment basis that combines different operations such as assembly, scientific research, logistics, maintenance and other ISS systems and utilization operations. With the advent of the ISS, the LeRC Microgravity Science Division (MSD) has a responsibility to develop the necessary telescience capability to support these missions on the International Space Station.

The concept of telescience will provide ground operators and Principal Investigators with the ground facilities and operations capabilities required to train for, simulate, and support a mission. The NASA Lewis Telescience Support Center (TSC), located at NASA Lewis Research Center, will provide the systems and services required to perform telescience. Prior to ISS, the NASA LeRC TSC has provided varying levels of operational support for over 16 Shuttle missions and 35 payload operations teams, including a remote science operations site (SOS) at Rensselaer Polytechnic Institute. With this past experience, LeRC is in an excellent position to transition to long duration ISS ground operations.

\section{Concept of Telescience}

The concept of telescience is to provide a complete and comprehensive end-to-end solution for controlling experiment hardware on-board the International Space Station (ISS). With this in mind, telescience actually begins with the onboard experiment hardware and ends with the experiment investigator. Although numerous interfaces exist in between the investigator and the on-board experiment hardware, the principle of telescience is to make the interfaces as 
transparent as possible and ideally no different than if the experiment hardware was actually sitting next to the investigator on the ground. This concept is depicted in Figure 1.0.

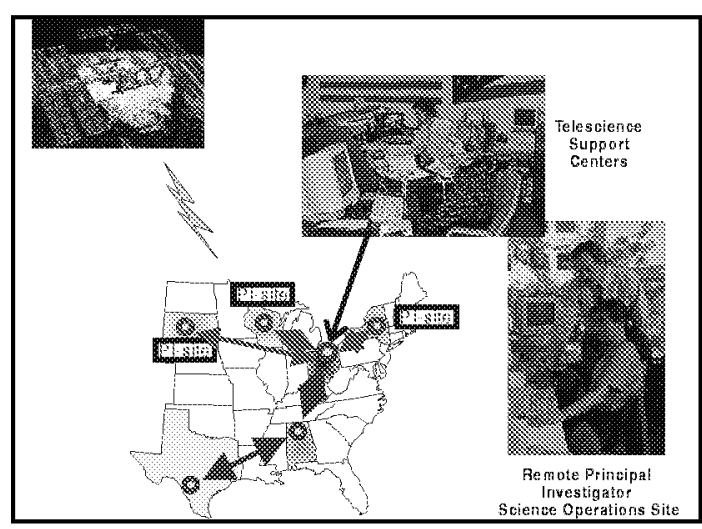

Figure 1.0 ISS Concept of 'Telescience

\section{Benefits of Telescience}

The benefits of telescience are numerous. The flight operations benefits include the following:

- Reduction or elimination of crew intervention

- Increases ability to automate experiment operations

- Increases the efficient use of on-board resources (ie: crew time, power)

- Optimizes real-time operations thus increasing return on science

- Improves ability to resolve anomalies and assure success of science objectives

The ground operational benefits include the following:

- The real-time experiment command and control capability reside at the home site of the Principal Investigator (PI) and the Engineering Team

- Enhances the ability to support long duration science experiments in space

- Increases the ability of the PI to interact with the experiment thus increasing the quality and return of science data

- Increases the visibility and community interest in ISS research

- Cost savings through the standardization and reuse of methods and ground operations equipment

\section{Ground Architecture}

Depicted in Figure 2.0, is a simplified ISS Flight to Ground Architecture, which includes the ground segment of the distributed operations concept. The ISS ground segment is comprised of the Mission Control Center (MCC), located at NASA Johnson Space Center (JSC), the Payload Operations Integration Center (POIC), located at Marshall Space Flight Center (MSFC), and TSCs, located at AMES, LeRC, MSFC, and JSC. The TSCs serve as a key component of the end to end International Space Station (ISS) ground segment. Together with the POIC, and the MCC, the TSCs will provide the set of tools and services required to fully enable remote operations at a Science Operations Site (SOS) for an individual investigator.

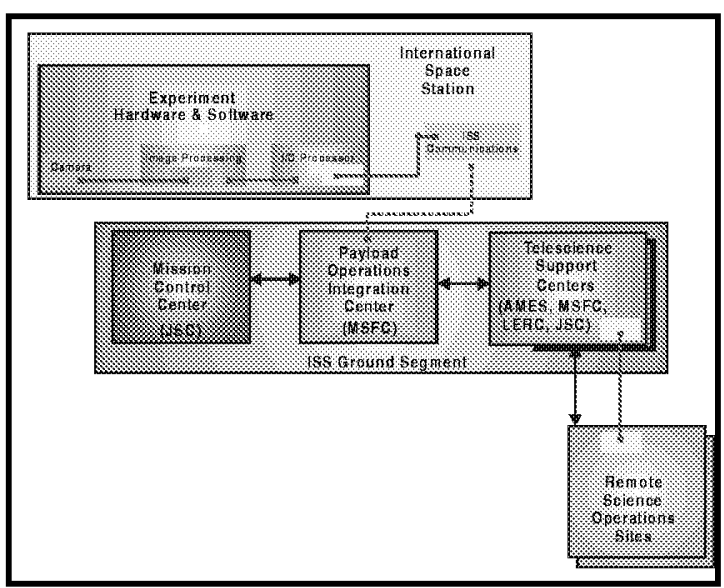

Figure 2.0 ISS Flight to Ground Architecture

\section{NASA LeRC Telescience Concept Implementation}

The following paragraphs provide a detailed description of the NASA LeRC implementation of the telescience concept as it applies to the ISS experiments that are developed and performed at NASA LeRC. The LeRC Space Directorate is composed of two groups that are currently developing experiment hardware for the ISS. The Microgravity Science Division (MSD) is responsible for microgravity investigations in combustion and fluid science research. The Power and Propulsion Office is responsible for advanced space power investigations. The development and operations of the LeRC TSC is under the Microgravity Science Division with $95 \%$ of its total use devoted to microgravity research. 


\section{$\underline{\text { LeRC TSC Interface Description }}$}

The primary interfaces from and to the TSC are shown in Figure 2.0. The TSC to POIC interface includes access to the Payload Data Services System (PDSS), the Payload Planning System (PPS), the Enhanced Huntsville Operations Support Center (HOSC) System (EHS), data distribution and the Enhanced Mission Communications System (EMCS) for voice distribution. The TSC interfaces to JSC for ISS video distribution. The TSC interfaces to the Principal Investigator SOSs for Telescience Resource Kit workstations (TreK), which is a personal computer based ground operations console, voice and video communications, distribution of air-to-ground voice, and video tele-conferencing. The TSC will also support an interface to local payload developer off-line operations areas for a telemetry only type of interface. Collectively, this set of tools and capabilities perform command processing, real time and near real time telemetry processing, and ground personnel communications for pre-launch integration and checkout, simulation training, and flight operations. Additional details on the ground support architecture and system capabilities are contained in the Payload Operations and Integration Center (POIC) Capabilities Document, SSP 50304, the LeRC-TSC Operations Concept Document, LeRC-TSC-003, and the TSC Implementation Plan, LeRC-TSC-004.

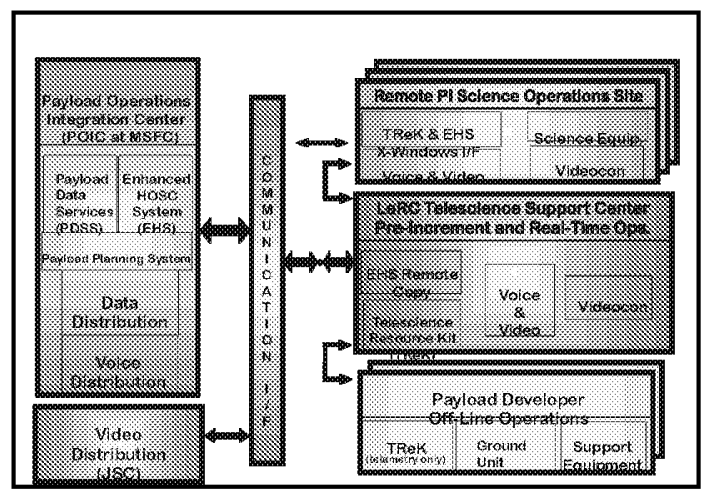

Figure 3.0 TSC Interfaces

\section{$\underline{\text { Telescience Support Center }}$}

The TSC will is located at NASA Lewis Research Center and currently resides in Building 333. The TSC will host the LeRC operations teams for microgravity and nonmicrogravity operations activities. The ultimate goal for the TSC is to ensure that all programmatic, system, and customer requirements are identified and accommodated by the design, implementation and procedures for operating the facility.

The TSC objectives are:

- To design, operate and maintain a secure operations facility for ground support personnel (GSP) to monitor, command, and control experiments onboard the ISS

- To provide a capability for training g.s.p., performing simulations, and mission operations at the TSC and/or at remote SOS.

The TSC will be ready for early payload operations starting with the ISS 6A flight, currently scheduled for April 2000. By the UF3 flight, currently scheduled for October 2002, the TSC will be fully operational. At the completion of the Fluids and Combustion Facility in 2004, the TSC anticipates operating continuously to support the 10-20 investigations per year that the FCF will accommodate. The following table identifies the ISS Early Utilization Traffic Model for the planned operations at the TSC.

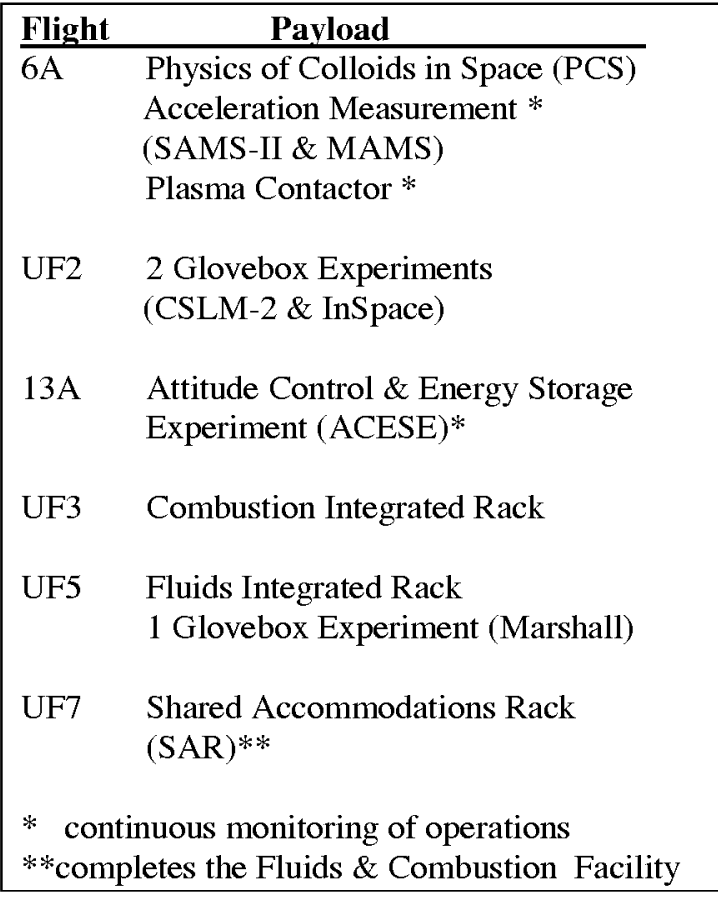

Table 1.0 LeRC ISS Utilization Traffic Model 


\section{TSC System Requirements}

The TSC system requirements are derived from the International Ground System Segment Specification, SSP 54500. This serves as the starting point for defining and evaluating the top level system requirements. In addition, and equally important, is the input provided by the future users of the TSC. Locally, a Telescience Working Group has been formed to help cultivate the identification and definition of payload developer operations concepts and requirements to assure that the TSC system requirements and design will in fact meet the envelope of individual user requirements. The TSC system requirements are documented in the LeRC TSC Requirements Document, TSCDOC-002. Subsequent to the definition of the TSC system requirements, increment specific ground data services are submitted by the individual payloads into the ISS Payload Data Library. All of the individual payload requirements that operate from the LeRC TSC, along with their remote SOS requirements, are then integrated for a single increment. For example, the payloads identified for the 6A flight, or ISS increment 2, for PCS, SAMS-II, MAMS, and Plasma Contactor are integrated into a set of increment specific requirements. The set of increment specific requirements establish the baseline services and allocation of resources for that increment.

The individual project manager and the Principal Investigator develop the requirements for the SOS. Payload requirements for the SOS are also submitted to the Payload Data Library. The TSC will be responsible for SOS service requirements for equipment and/or services that are actually supplied by the TSC. For example, the TSC will be responsible for configuring and deploying TreK systems to the SOS for use during the increment. The TSC will not be responsible for SOS service requirements for equipment and/or services that originate from MSFC or JSC. For example, JSC is responsible for ISS video distribution that comes directly from JSC.

\section{TSC Development Approach and Status}

The TSC development approach is phased as two development activities. Phase 1 of the TSC will accommodate the early payload operational requirements starting with $6 \mathrm{~A}$, through $13 \mathrm{~A}$ with 1 planned SOS. Phase 2 of the TSC will increase capability to accommodate the FCF facility class payload and multiple SOSs starting with UF3. The following paragraphs describe the Phase 2 implementation approach.

\section{$\underline{\text { TSC Systems Description }}$}

Based on the requirements in the TSC Requirements Document, TSC-DOC-002, the following systems have been defined to support telescience operations. Figure 4.0 shows a top level diagram of the TSC system.

The TSC systems include:

- Data and Commanding

- Audio System

- Video System

- Telecommunications \& Networking

- Ground Track \&Timing

- Video Tele-Conferencing

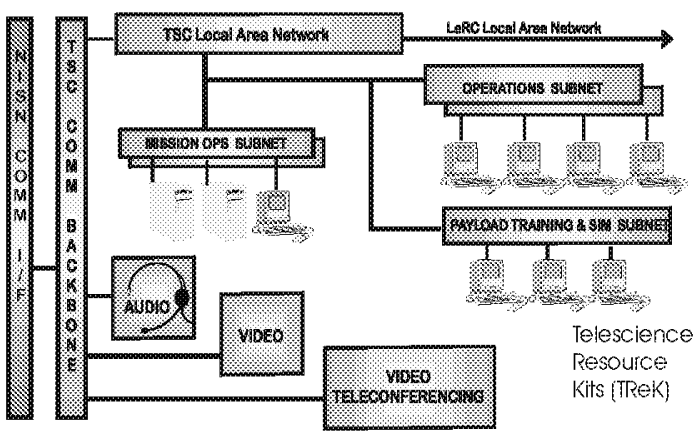

Figure 4.0 TSC Architecture

\section{Data \& Commanding}

The data and commanding system provides a capability for requesting, receiving, storing, processing, and displaying telemetry data, commanding the on-board hardware, and access to other ISS mission services. The TreK system serves as the standard user interface to the TSC data and commanding system. The TreK system consists of a personal computer which is configured with commercial off the shelf software, shareware, and freeware, and interface software provided by MSFC. TreK systems will be used at both the TSC and at the SOSs. In addition, the TSC will host a remote copy of the MSFC provided EHS. All TSC and SOS TreK workstations will interface to the TSC copy of the EHS. In addition, the remote copy of the 
EHS will support local database management for commanding and telemetry which is essential for managing multiple SOSs for the FCF.

\section{Audio System}

The audio system provides a capability for receiving and transmitting signals from and to the MSFC voice distribution system. Individual voice loops will be distributed to Operator Communications Panels at each console location in the TSC and will provide access to local and ISS voice loops. Audio distribution to SOSs will be supported either through the use of remote operator communication panels or over the internet. Voice distribution over the internet is under evaluation.

\section{Video System}

The TSC video system provides a capability for distributing, accessing, displaying, and recording ISS downlink video. Each console location will have a video monitor and a video channel matrix which will provide individual control of video selection. Video distribution to SOSs will be directly from JSC over domestic satellite. Video over the internet is also being evaluated as a potential solution for video distribution to SOSs.

\section{Telecommunications \& Networking}

The TSC telecommunications and networking system serves as the primary communications link between the NASA Integrated Services Network (NISN) and the LeRC TSC internal network. NISN is responsible for all of NASA's wide area network telecommunications services for the transmission of data, video, and voice. Commercial capabilities will be utilized werever possible. Telecommunications to the SOSs are also the responsibility of NISN and implementation plans are undefined at this time.

\section{Ground Track \& Timing}

The TSC Ground Track provides displays of ISS on-orbit and predicted Tracking and Data Relay Satellite (TDRS) acquisition of signal and loss of signal (AOS/LOS) times. The Ground Track and AOS/LOS displays are generated by computers and sent to the video matrix system for distribution to TSC users. If requested, a ground track system could be provided to a SOS.
The TSC timing system provides displays of ISS real-time and simulated times. The timing system accepts the IRIG-B Greenwich Mean Time (GMT) signal and creates displays that are distributed throughout the TSC using the TSC video matrix.

\section{Video Conferencing}

The TSC video-conferencing system will support bi-directional audio and video communications with other NASA centers and SOSs. Videoconferencing at SOSs will also be supported but the implementation is undefined at this time.

\section{Facility Accommodations}

The facility accommodations will include the following functional areas:

- Operations areas for payload experiment team console activities

- Operations control area for TSC staff

- Training facility

- Communications interface and data system server area

- Data system development \& validation, system-administration, and workstationstaging area for TSC staff to perform data system related tasks

- Video Conferencing area

- Meeting rooms for replanning activities and shift hand-over functions

- $\quad$ Spares \& equipment storage

- Document \& drawing storage

- Common services area for printers, scanners, copiers, fax machine, and supplies

\section{Science Operations Site Description}

Due to the uniqueness of each microgravity investigation, SOS's will vary in the level of functionality required. The following description is provided as a general idea of what a SOS would look like and is not meant to be allinclusive nor constraining to the development of a future SOS. Each Principal Investigator will work with the NASA Project Manager to identify and develop the appropriate operations concept that meets the goals of the investigation. Each SOS will be fairly unique in the sense that each one has different methods, approaches, and 
functions that could be performed at the SOS. The first decision is to determine if a remote SOS is appropriate. Once the decision is made to set up a SOS at the PI's home location, an operations concept which defines roles and responsibilities of the NASA Engineering team and the Science Team would be developed to help identify appropriate requirements to submit to the Payload Data Library. Items to be considered include:

- Duration of experiment operations

- Assessment of existing services at the SOS

- Physical location of SOS

- Security requirements for the SOS

- Functions to be performed at the SOS

- Communications with Engineering Team

- Science telemetry data monitoring or monitoring and commanding

- Video requirements

- Video and/or teleconferencing requirements

- Other service requirements

As a minimum, it is envisioned that a PI would require a TreK system, access to internet services, some type of NASA wide area network interface, voice communications, and a teleconferencing capability.

\section{Security}

The TSC shall implement a security program that is based on its NASA mission and National Policy. Security requirements shall also be imposed on the SOSs and will be their responsibility to implement.

\section{Training and Certification}

A certified TSC trainer will provide training and certification to all Ground Support Personnel that operate from either the TSC or SOSs. User training and certification will consist of:

- Generic user training on security policies and on the operations of TSC provided voice, video equipment, and TReK workstations

- Increment-specific training for operations that are coordinated with MSFC, JSC, and SOSs

- User certification will be in accordance with programmatic requirements to be defined in the Payload Ground Support Personnel Training and Certification Plan

\section{$\underline{\text { Summary }}$}

As the era of the ISS becomes a reality, telescience will assure the optimization of science and technological data return. Principal Investigators will be able to monitor and control experiment hardware on-board the ISS independent of his/her geographical location. The distribution of ground operations will maximize the use of the ISS by increasing the amount and quality of data returned to the investigator. At NASA LeRC, the TSC is being developed to fully accommodate telescience either from the TSC or from a remote PI science operations site. The phased development approach will respond to user requirements by providing a cost-effective design that allows for maximum capability. In addition, many innovative solutions such as voice and video over the Internet are being evaluated across the ISS program, which will reduce cost and increase telescience capability for the experimenter for the minimum investment of resources.

\section{$\underline{\text { References }}$}

LeRC TSC Requirements Document, TSC-DOC-002

LeRC TSC Operations Concept Document, TSC-DOC-003

LeRC TSC Implementation Plan, TSC-DOC-004

International Ground System Specification, SSP 54500, Appendix F

POIC Capabilities Document, SSP-50304

POIC Generic User Interface Definition

Document, SSP-50305 
\begin{tabular}{|l|c|c|}
\hline 1. AGENCY USE ONLY (Leave blank) & $\begin{array}{c}\text { 2. REPORT DATE } \\
\text { February } 1999\end{array}$ & $\begin{array}{r}\text { 3. REPORT TYPE AND DATES COVERED } \\
\text { Technical Memorandum }\end{array}$ \\
\hline
\end{tabular}

\section{TITLE AND SUBTITLE}

Telescience Operations on International Space Station

6. AUTHOR(S)

Kathleen E. Schubert

\section{PERFORMING ORGANIZATION NAME(S) AND ADDRESS(ES)}

National Aeronautics and Space Administration

Lewis Research Center

Cleveland, Ohio 44135-3191

9. SPONSORING/MONITORING AGENCY NAME(S) AND ADDRESS(ES)

National Aeronautics and Space Administration

Washington, DC 20546-0001
WU-479-85-01-00

8. PERFORMING ORGANIZATION REPORT NUMBER

E-11525

10. SPONSORING/MONITORING AGENCY REPORT NUMBER

NASA TM-1999-208910

AIAA-99-0319

\section{SUPPLEMENTARY NOTES}

Prepared for the 37th Aerospace Sciences Meeting \& Exhibit sponsored by the American Institute of Aeronautics and Astronautics, Reno, Nevada, January 11-14, 1999. Responsible person, Kathleen E. Schubert, organization code 6727, (216) 433-5331.

Unclassified - Unlimited

Subject Category: 14

Distribution: Nonstandard

This publication is available from the NASA Center for AeroSpace Information, (301) 621-0390.

\section{ABSTRACT (Maximum 200 words)}

This paper describes the concept of telescience operations for the International Space Station (ISS). The extended duration microgravity environment of the ISS will enable microgravity science research to enter into a new era of increased scientific and technological data return. The National Aeronautics and Space Administration (NASA) has a vision of distributed ground operations which enables the Principal Investigator direct interaction with his/her on-board experiment from his/her home location. This is the concept of telescience and is essential for maximizing the use of the long duration science environment that ISS provides. The goal of telescience is to provide the capability to fully tele-operate an experiment from any ground location in such a way as to increase the amount and quality of scientific and technological data return and decrease the operations cost of an individual experiment relative to the era of Space Shuttle experiments. This paper also describes the NASA Lewis Research Center (LeRC) implementation approach for the LeRC Telescience Support Center (TSC) and Principal Investigator Science Operations Sites (SOS) which will fully meet the concept of telescience as prescribed by the Agency.

\section{SUBJECT TERMS}

International Space Station; Ground support systems

\begin{tabular}{|c|c|}
\hline $\begin{array}{c}\text { 17. SECURITY CLASSIFICATION } \\
\text { OF REPORT } \\
\text { Unclassified }\end{array}$ & $\begin{array}{c}\text { 18. SECURITY CLASSIFICATION } \\
\text { OF THIS PAGE } \\
\text { Unclassified }\end{array}$ \\
\hline
\end{tabular}

19. SECURITY CLASSIFICATION OF ABSTRACT

Unclassified
15. NUMBER OF PAGES

12

16. PRICE CODE

20. LIMITATION OF ABSTRACT

Standard Form 298 (Rev. 2-89)

Prescribed by ANSI Std. Z39-18 298-102 